\title{
The Case Against Representationalism About Moods
}

Amy Kind

This is the penultimate draft of a paper that will appear in Current Controversies in the Philosophy of

Mind edited by Uriah Kriegel (Routledge 2013). All citations should be to the published version.

Despite the enormous neuroscientific progress of the last half century, the phenomenon of consciousness remains largely a mystery. Fortunately, with respect to one large class of unanswered questions about consciousness, unraveling the mystery looks to be only a matter of time. Questions broadly relating to the information-processing side of consciousness, for example, all look eventually answerable in neuroscientific or computational terms. Such questions thus constitute what are often called the easy problems of consciousness. Although such questions may well take us decades to solve, they do not seem beyond the realm of our standard physicalist framework. Contrast such questions, however, with what's known as the hard problem of consciousness, the problem of conscious experience. Our inner life is filled with vivid sensations of color and sound, with pulsing pains, with deeply felt emotions and moods. Consider the experience of seeing the rich hues of a peacock's plumage, of hearing the sonorous tones of a grandfather clock, of stubbing a toe against the wall, of overflowing with happiness, or of sinking deeper into an all-encompassing depression. With respect to conscious experiences such as these, it looks considerably less likely that standard scientific explanations will eventually be forthcoming. No matter how much we learn about a given neural process, it seems that we still won't have explained how the process gives rise to this particular conscious experience - or why it gives rise to any conscious experience at all. Conscious experience - often referred to as phenomenal experience or phenomenal consciousness - threatens to escape our physicalist net and potentially remain entirely outside the domain of scientific inquiry. ${ }^{1}$

Over the last couple of decades, many philosophers have attempted to defuse this threat by showing that phenomenal consciousness can be understood in terms of the technical notion of intentionality. The philosophical terminology is somewhat unfortunate here, since this sense of "intentional" has nothing to do with the ordinary notion of being purposively brought about. Rather, to say that a mental state is intentional in this technical sense - stemming from the Latin intendere, which means to aim at, as with a bow - is to say that it is directed at or about something, i.e., that it is representational. Beliefs, desires, and perceptions are all paradigmatic examples of intentional states. My visual perception of the can of Diet Coke on my desk, my belief that it is half full, and my desire to have a sip from it, are all intentionally directed at the can on my desk. Importantly, mental states can have intentionality even if they're intentionally directed toward something that does not exist. My belief that Vulcan is a planet is about Vulcan, even though no such heavenly body exists.

Giving an acceptable physicalist account of intentionality is no trivial matter, but most philosophers believe that this task can eventually be accomplished. If they are right, then the successful

\footnotetext{
${ }^{1}$ The easy/hard terminology derives from David Chalmers. Much of the contemporary discussion of the hard problem of consciousness owes to his work (see, e.g., Chalmers 1995).
} 
reduction of a state's phenomenal character to its intentional content would in turn provide a solution to the hard problem of consciousness. ${ }^{2}$ The theory of consciousness that attempts this reduction is known as representationalism, or more specifically, strong representationalism. Some proponents of this theory call their view strong intentionalism, but the two terms are used interchangeably in the literature, and in what follows, I adopt the former terminology.

Strong representationalism contrasts with weak or non-reductive representationalism. While strong representationalists attempt to reduce phenomenal character to intentional content, weak representationalists claim only that phenomenal character supervenes on intentional content (see, e.g., Crane 1998, Chalmers 2004). Weak representationalism, however, does not aim to provide a theory of what phenomenal character is, and correspondingly, does not offer a solution to the hard problem of consciousness. In what follows, my discussion will be directed at strong representationalism, the reductive version of the view. ${ }^{3}$ As is common in the literature surrounding this theory, I will hereafter drop the qualifier "strong" and refer to the view in question simply as representationalism.

Representationalism seems comparatively plausible with respect to ordinary perceptual experiences: When I look at a sunflower, the fact that my visual experience has the particular yellowish phenomenology that it does seems closely tied to the fact that it represents the yellow sunflower. ${ }^{4}$ It's perhaps for this reason that much of the work on representationalism has concerned perception, and specifically, visual perception. But most representationalists nonetheless endorse an unrestricted version of the theory: For any state with phenomenal character, the state's phenomenal character reduces to its intentional content. Only unrestricted representationalism can offer us a theory about the nature of phenomenal character in general, and it thus seems that the plausibility of the view hinges in large part on its applicability across all phenomenal states. ${ }^{5}$

Much of the debate about the viability of unrestricted representationalism has focused on phenomenally conscious states that seem to lack intentionality altogether. Since a state's phenomenal character will not be reducible to its intentional content if the state does not have any intentional content, any non-intentional states serve as counterexamples to an unrestricted representationalist thesis. Despite Brentano's famous claim that intentionality is the mark of the mental - that all mental

\footnotetext{
${ }^{2}$ Charles Siewert provides a particularly clear explanation of the motivation behind strong representationalism: "One may believe that it offers us the only hope for a natural scientific understanding of consciousness. The underlying thought is that a science of consciousness must adopt this strategy: first conceive of intentionality (or content or mental representation) in a way that separates it from consciousness, and see intentionality as the outcome of familiar (and non-intentional) natural causal processes. Then, by further specifying the kind of intentionality involved (in terms of its use, its sources, its content), we can account for consciousness. In other words: 'naturalize' intentionality, then intentionalize consciousness, and mind has found its place in nature." (Siewert 2006).

${ }^{3}$ Although I here target only strong representationalism, some of my criticisms apply to weak representationalism as well.

${ }^{4}$ This should not be taken as an endorsement of representationalism with respect to perceptual experiences. See, e.g., Kind 2008 for arguments against representationalism even in the perceptual case.

${ }^{5}$ There is agreement on this point by both representationalists and non-representationalists. For example, I make this point in Kind 2007 in the context of arguing against representationalism, while Byrne 2001 and Mendelovici (this volume) make this point in the context of arguing for representationalism.
} 
states have intentional content - there nonetheless seem to be examples of phenomenally conscious states that lack intentionality altogether. When I press on my eyeball, thereby creating a phosphene experience, that experience does not seem to be about anything. And while bodily sensations like pain might be intentional, representing bodily damage, it is less clear how we could identify intentional content for bodily sensations like tickles and orgasms. Finally, consider mood states like generalized elation or depression, or free-floating anxiety. Although oftentimes I am elated, depressed, or anxious about particular things or happenings in the world, it seems that sometimes these states can occur without being directed or about anything at all.

In this essay, I explore this last category of potential counterexamples to representationalism. Moods have long proven to be a particularly thorny problem for representationalists, and even some of the staunchest among them have simply thrown up their hands when trying to identify a plausible candidate for the intentional content of moods. Fred Dretske, for example, hedges his bets when claiming that all mental facts are representational facts by adding the phrase "plus or minus a bit". The qualifier is needed, he notes, because there are some "experiences-a general feeling of depression, for example-about which I do not know what to say." (Dretske 1995, xv)

My investigation into the plausibility of representationalism as applied to moods will require me first to explore what exactly moods are, and whether and how they are to be differentiated from other affective states like emotions. This leads in turn to a discussion of the intentionality of moods. Although moods have often been claimed to be non-intentional, I will concede to the representationalist that this claim should be rejected. To my mind, the plausibility of representationalism turns not on the question of whether moods have intentional content but rather on whether the intentional content of moods is sufficient to determine their phenomenal character. I will argue that it does not. Ultimately, then, I conclude that moods do indeed pose a serious objection to the representationalist theory.

\section{Moods vs. Emotions}

The contemporary philosophical literature contains surprisingly little philosophical discussion of moods, and even less devoted to moods in and of themselves. ${ }^{6}$ What little discussion there is tends to occur in the context of discussing emotion. This is perhaps not surprising given the deep similarities between moods and emotions. For every mood state, there seems to be a corresponding emotion state, often identified by the very same term. Compare being in an anxious mood with one's anxiety about a particularly steep segment of a hike, or being in a fearful mood with one's fear when a rattlesnake suddenly appears on the trail ahead, or being in an elated mood with one's elation upon reaching the mountain summit.

In fact, there is considerable disagreement about whether emotions and moods should be classified together or treated separately as different kinds of mental states. For some philosophers, the difference between emotion and mood is just, as Peter Goldie puts it, "a matter of degree" (Goldie

\footnotetext{
${ }^{6}$ Three notable exceptions include Lormand 1984, Griffiths 1989, and Sizer 2000.
} 
2000, p. 17), where moods are simply more diffuse or "generalized" emotions. ${ }^{7}$ My own inclination, however, lies with the philosophers who separate out moods from the class of emotions, i.e., who insist that a proper classification of our mental states not lump emotion and mood together. ${ }^{8}$ In most cases, the argument for drawing a distinction relies on the fact that moods and emotions play different functional roles and/or have different functions in our mental life as a whole. Carolyn Price, for example, contrasts the functional roles played by the emotion of fear and a fearful mood: While experiencing the emotion of fear has the function of enabling a subject to deal effectively with an occurrent threat, being in a fearful mood has the function of adapting the subject to an environment in which a threat is likely. (Price 2006, p. 57) For Paul Griffiths, moods contrast with emotions in virtue of being higher-order functional states. (Griffths 1989) ${ }^{9}$

In the empirical literature on affect, researchers tend to draw a sharp distinction between moods and emotion, although there is not widespread agreement on the exact characteristics that distinguish them. ${ }^{10}$ Among the numerous criteria proposed, one of the most common concerns the duration of the state in question. Emotions are thought to be affective states of relatively brief duration, while moods are affective states of more sustained duration. The duration criterion, which is echoed in the philosophical literature as well, enjoys considerable intuitive plausibility, as it matches up well with typical episodes of both emotions and moods: Emotions are fleeting, lasting sometimes just mere seconds and at most a few minutes, while moods tend to last for a considerably longer periods of time. In evaluating this criterion, however, we must ask whether this is always the case. Although moods are typically long-lasting, there are plausible cases in which they are relatively brief. An unexpected act of deep kindness, for example, might shake someone from her gloomy mood very shortly after its onset. Conversely, although emotions are typically short-lasting, there do seem to be cases where they are sustained over a considerable period of time. Might not a strong-willed child fume with anger for hours? Or consider a mild claustrophobic trapped in an elevator for an entire morning. Can't we easily imagine her terror lasting the entirety of the episode? It thus seems unlikely that duration is either necessary or sufficient to differentiate moods from emotions. ${ }^{11}$

A second criterion commonly offered in both the psychological and philosophical literature, and one that is especially relevant for our overall purposes here, concerns the intentionality of these states. Emotions are thought always to be directed at something determinate. When we're fearful, or angry, or

\footnotetext{
${ }^{7}$ Solomon uses the term "generalized emotion" (Solomon 1993, p. 71); Frijda refers to moods as "diffuse" (Frijda $1994,60)$. Other philosophers who treat moods as a subclass of emotions include Prinz 2004 (pp. 182-8), Fish 2005, DeLancey 2006, and Mendelovici (this volume).

${ }^{8}$ Although going forward I will assume that emotions and moods are distinct, this assumption is not critical for my argument; the failure of representationalism to account for moods is just as problematic for the theory if moods are merely a subclass of emotions than if they form a distinct class of mental state.

${ }^{9}$ Other philosophers who explicitly distinguish moods from emotions include Lormand 1984, Montague 2009, DeSousa 2010, and Sizer 2000. In presenting her computational analysis of moods, Sizer challenges not only the assumption that moods and emotions are essentially the same type of state but also the assumption that "one theory or explanatory apparatus can be applied to all types of affect." (2000, p. 748)

${ }^{10}$ See, e.g., Davidson and Ekman 1994, 94.

${ }^{11}$ For related considerations against the duration criterion, see Lazarus 1984 and Prinz 2004, p. 183.
} 
disgusted, there's always some particular thing - an object, a person, an event, a state of affairs - at which our fear, anger, or disgust is directed. ${ }^{12}$ This gives us a claim I'll call the Directedness of Emotions:

(DE) Emotions are always directed at something particular.

Moods, in contrast, lack the kind of intentional determinateness that is characteristic of emotions. As the psychologist Nico Frijda puts in, moods are distinguished by their "absence of orientation around an object." (Frijda 1993, p. 381). This seems clearest, perhaps, when considering states like free-floating anxiety or ennui, but it holds broadly across the whole spectrum of moods from ebullience to depression. This gives us a claim that I'll call the Undirectedness of Moods:

(UM) Moods are typically not directed at anything particular.

Sometimes in the literature one finds an even stronger claim, what l'll call the Strong Undirectedness of Moods:

(SUM) Moods are never directed at anything particular.

Proponents of SUM include Julien Deonna and Fabrice Teroni; as they argue, it does not make sense to restrict the attribution of a mood to a particular object or objects: "One is in a gloomy, grumpy or joyful mood, never gloomy or grumpy about Mike or about the rich." (Deonna and Teroni 2012, p. 4) ${ }^{13}$

Initially, it may seem that SUM is too strong. Isn't it perfectly natural to describe someone as being grumpy about having lost a hard-fought soccer match, or joyful about the birth of a child? Can't moods in this way be connected with particular incidents or things, just as emotions can? To my mind, the proponent of SUM has two natural ways to respond to these putative counterexamples. First, she might note that in some such cases we are not really picking out a person's mood but rather the corresponding emotion. Second, in cases where we really have identified a grumpy or joyful mood and not simply a grumpy or joyful emotion, she might note that the particular incident or thing pointed to is best understood as the cause of the mood rather than what the mood is directed toward - mood reports use the causal and not the intentional sense of "about." To say that someone is grumpy about having lost a close soccer game, for example, is to say that her grumpiness was caused by the loss; now ensconced in a state of grumpiness, her mood seems no more directed at the soccer game in particular than it is at anything else in the world.

Whether this defense of SUM is successful is fortunately not a matter we need to settle here. In what follows, I will assume only the weaker UM, a claim about which there is a widespread consensus. ${ }^{14}$

\footnotetext{
12 This does not mean that we must always be able to correctly identify the objects of our emotions. Awoken by a strange sound in the middle of the night, I might have a feeling of fear without quite knowing what I am fearful about.

${ }^{13}$ See also Thalberg 1964. According to Thalberg, states like depression, euphoria, total apathy, and free-floating anxiety, etc., cannot take objects.

${ }^{14}$ One philosopher who objects even to the weaker UM is Craig Delancey. According to Delancey, the fact that we cannot identify the particular object of a mood does not mean that there is no such object: "Since the only evidence for the lack of objects for moods is phenomenological, then the fact that moods sometimes appear to
} 
But what about $\mathrm{DE}$, the claim that emotions are always directed at something in particular? Although there is widespread agreement about the truth of this thesis as well, it's not clear that DE is immune to counterexample. One might all of a sudden be panicky, or angry, without being panicky or angry about anything in particular. ${ }^{15}$ Or consider the emotions aroused by listening to music - the exaltation brought on by various marches or the yearning brought on by romanticist chamber music. In an interesting discussion, Joel Kupperman notes that such emotions seem to have a peculiarly free-floating quality; when listening to a Brahms quartet piece, for example, the bittersweet feelings aroused do not seem to be about the music itself, nor about anything at all. (Kupperman 1995)

If any of these purported examples of non-intentional emotions were to hold up to scrutiny, they would serve as counterexamples not only to DE but to representationalism as well. Since I lack the space here to explore these cases in any detail, I will refrain from relying on them in my case against representationalism; in what follows, I will simply grant the truth of DE.

\section{The Intentionality of Moods}

Above we saw that there is widespread consensus that moods, unlike emotions, are typically not directed at anything in particular. But some philosophers move quickly from UM to a further claim that I'll call the Non-Intentionality of Moods:

(NIM) Moods are typically non-intentional.

The move from UM to NIM is unusually explicit in the following passage from Deonna and Teroni:

Moods, like emotions, have a characteristic phenomenology. ... Unlike emotions, however, and this is the principled distinction between the two types of affective phenomena, moods do not appear to be intentional in that they never target specific objects. [my emphasis] (Deonna and Teroni 2012, p. 4)

But Deonna and Teroni are not alone in making this move. Consider John Searle's influential treatment of intentionality:

Beliefs, fears, hopes, and desires are Intentional; but there are forms of nervousness, elation, and undirected anxiety that are not Intentional. A clue to this distinction is provided by the constraints on how these states are reported. If I tell you I have a belief or desire, it always makes sense for you to ask, "What is it exactly that you believe?" or "What is it that you desire?"; and it won't do for me to say, "Oh I just have a belief and a desire without believing or desiring anything". But my nervousness and undirected anxiety need not in that way be about anything. (Searle 1983, 2)

lack an object is not a distinguishing feature. They could have an object of which we are unaware; and they may have a series of objects, including unrelated objects. The same is true of emotions: they often do not have an object we can identify, and in fact, an emotion can occur and have measurable effects on us, even effects we are aware of, without our knowing we are in the emotional state." (DeLancey, 533)

${ }^{15}$ For discussion of objectless panic and objectless rage, see Price 2006, p. 52. 
For Searle, it's when moods are not directed at anything in particular that they become classified as nonintentional. ${ }^{16}$

If moods - or at least some moods - are as these philosophers describe them, then representationalism would be false for such states; the phenomenal character of a state cannot be reduced to its intentional content if the state has no intentional content. The truth of NIM, in other words, would make the anti-representationalist case an easy one. Unfortunately, things are not quite this simple. Several different kinds of proposals in the literature suggest ways that, despite the truth of UM, moods might have intentional content. Here I discuss each in turn.

\subsection{Moods as Generalized Representations (Outward Directedness)}

In moving from UM to NIM, the philosophers quoted above seem to be working with an objectoriented conception of intentionality, i.e., they take intentionality to consist in object-directedness. It seems implausible, however, that the kind of directedness involved in intentionality must be understood in such a narrow way. Once we broaden our conception of intentionality, moods can be seen to have intentional content even if they are not directed at anything particular.

Consider, for example, the fact that moods are often described - puzzlingly so - as being directed at both nothing and everything. ${ }^{17}$ The apparent puzzle quickly dissipates once we realize that what's meant is that moods are directed at nothing in particular by being directed instead at everything altogether. In contrast to the experience of an emotion which is directed at a specific target, moods have a more generalized directedness. But how should we understand the notion of generalized directedness?

This rough idea has been most commonly spelled out in two different ways, although I think they are often run together in the literature. ${ }^{18}$ Consider, for example, the following two passages:

Euphoria, melancholy, and depression are not about anything in particular (though some particular incident might well set them off); they are about the whole of our world, or indiscriminately about anything that comes our way, casting happy glows or somber shadows on every object and incident of our experience." (Solomon 1976, 173)

We are often unaccountably depressed, on days when for no reason everything seems black; but pointless depression is not objectless depression, and the objects of depression are the things which seem black. (Kenny 1973, p. 61)

One strand in these passages consists in the idea that the focus of moods varies widely through time - first the mood is directed on one thing, then another, and then another. Consider someone in

\footnotetext{
${ }^{16}$ See also George Graham's distinction between two kinds of depression, depression with intentionality and depression without intentionality (Graham 1990, 405-6).

17 See, e.g., Goldie 2000, p. 18; De Sousa 2010; Sizer 2000, p. 747.

${ }^{18}$ One place where they are very clearly distinguished is Tye 2008.
} 
the grips of ennui. Whatever she turns her attention to-first the food on the table in front of her, then the show playing on the television, then the book she's trying to read - strikes her as dull and uninteresting. And there's nothing special about ennui. If she were suffering from depression instead, then these same things might seem black, as Kenny suggests, or overcast with Solomon's "somber shadows"; in a euphoric mood, they might all seem bright and wonderful, infused by Solomon's "happy glows." 19

A second strand in these passages, and in the literature as a whole, consists in the idea that moods are directed not at a changing series of objects over time but broadly at the world at large; as William Lyons says, moods are "aimed out at the world" without coming to rest "in any one spot or on any one thing." (Lyons, p. 104) We see this idea in the passage from Solomon above when he talks of moods being directed at the "whole of our world." It is also reflected in Annette Baier's claim that moods have "near all-inclusive and undifferentiated objects," (Baier 1990, p. 3). ${ }^{20}$

Not everyone is convinced that all cases of moods fit into one of these two categories. As Mendelovici argues, some cases of anxiety or elation do not seem to be directed either at the world as a whole or at a changing series of objects; in such cases, one simply feels anxious or elated, full stop. Although Mendelovici thinks that we should take seriously the fact that such experiences appear to lack an intentional object, she does not think that this requires us to deny that moods have intentional content. Moods might lack an intentional object yet nonetheless be intentionally directed insofar as they represent properties.

This suggestion is best understood in relation to Mendelovici's account of the intentionality of emotions (this volume). Consider the fear I experience when I unexpectedly encounter a rattlesnake. My fear, in being intentionally directed toward the rattlesnake, represents the snake as scary. According to Mendelovici, the property of scariness - like rosiness, bleakness, and other properties represented by emotions - is a sui generis emotion-property, distinct from ordinary physical or dispositional properties, and not reducible to any other kinds of properties. To avoid confusion going forward, I will indicate these properties with an asterisk: scariness*, rosiness*, etc. In Mendelovici's view, then, my fear of the snake represents the snake as being scary*, a different property from the one picked out by the thought "The snake is scary."

Since it is implausible that objects in the world actually have the emotion-properties that our experiences represent them as having, Mendelovici embraces a form of projectivism about these properties. More specifically, she adopts the view known as figurative projectivism: It's not that these properties are instantiated somewhere else, but that they are not instantiated at all. We mistakenly attribute these emotion-properties to objects to mark the fact that the objects have significance for us. On her view, we should think of the different emotions as analogous to different highlighter colors - joy

\footnotetext{
${ }^{19}$ See also Tye 2008 and Sizer 2000 for discussions of elation and melancholy, respectively, along these lines.

${ }^{20}$ See also the psychologist Richard Lazarus's claim that moods reflect the "the existential background of our lives." (Lazarus 1994, p. 84)
} 
at the birth of a baby highlights the baby with a certain emotion-property, while sadness at the illness of a beloved friend highlights the friend with a different emotion-property.

Now consider a mood like free-floating anxiety, which does not appear to be intentionally directed at any object. ${ }^{21}$ For Mendelovici, such a mood represents the same kind of emotion-property that the corresponding object-directed emotion does, but in this case, the emotion-property is represented as unbound, i.e., not bound to any object. Moods, then, should be thought of as analogous to the color of the ink in a highlighter - in experiencing a mood, we experience the color of the ink though no particular thing or group of things is 'highlighted.' Mendelovici in this way gives us a third way to think of the generalized, outward-directedness of moods - such experiences strike us as more diffuse or generalized than emotions because they are not tied to particular objects or even series of objects. The free-floatingness of moods can be explained by the fact that they represent free-floating properties.

I will return to all three of these views in Section 3, below. For now, however, what's important to note is that if any of these three views provides a plausible understanding of the generalized directedness of moods, NIM would turn out to be false.

\subsection{Moods as Sensory Representations of Bodily States (Inward Directedness)}

Suppose at this point we were simply to dig in our heels and deny that all moods must be outwardly directed. There might be a mood, a feeling of elation perhaps, that is not about a changing series of objects in the world, or the world as a whole, or even about unbound elatedness. Although it might seem that such a mood would have to be non-intentional, many philosophers have denied this claim. Even if we grant that there could be such a mood entirely lacking in outward directedness, the mood might still have a kind of inward directedness.

Here it's instructive to compare recent discussion of the intentionality of pain. A long tradition in philosophy had classified pain - along with other bodily sensations, and also states like both emotions and moods - as non-intentional. Consider, for example, Louise Antony's suggestion that "things like pleasures, pains, moods and emotions don't, on the face of it, appear to be about anything at all" (Antony 1997, p. 25). ${ }^{22}$ Against this tradition, many philosophers have recently argued for a perceptual account of bodily sensations: Just as a visual experience provides us with perceptual awareness of the world, a sensation provides us with perceptual awareness of the body. Pain can thus be understood as a sensory representation, one that represents a particular bodily disturbance. When you cut your finger, your pain represents the tissue damage in that finger; after a strenuous workout, your aches represent

\footnotetext{
${ }^{21}$ As noted above in Section 1, Mendelovici thinks of moods as a sub-class of emotions and correspondingly refers to them as the undirected emotions. In explaining her view, I have modified her terminology to correspond with the terminology I am using here.

${ }^{22}$ See also Colin McGinn's claim that "bodily sensations do not have an intentional object in the way perceptual experiences do." (McGinn 1997, pp. 8-9)
} 
the condition of your muscles. ${ }^{23}$ In some cases, we might be in pain without any corresponding bodily damage, but such cases are simply instances of misrepresentation.

Thus, , insofar as pains carry information about the states of our body they can, contra Antony, be understood as intentional. This general analysis might then be extended to emotions and moods. First consider emotions. Instances of emotions typically are associated with various physiological changes, from flushed cheeks and sweaty palms to a racing pulse and shortness of breath. Different philosophical theories of the emotions explain this association in different ways. William James, for example, famously argued that emotions are to be identified with the experiences of physiological changes; as natural as it might be to think that my pulse is racing and I'm short of breath because I'm afraid, in fact it's the experience of these bodily changes in which my fear consists. (James 1884) In recent years, James' theory has largely fallen into disfavor - among other problems, it's not at all clear that the physiological profiles of differing emotions are sufficient to individuate them. But even assuming there is more to emotion than just the experience of physiological changes, it's nonetheless plausible to suppose that emotions are - at least in part - representations of such changes. ${ }^{24}$

Moods, unlike pains and emotions, are not associated with specific or easily identifiable physiological changes. Yet like pains and emotions, they seem to be importantly tied to our bodies. In attempting to flesh out this thought, it might be claimed that moods have a more general representational function, namely, to represent the overall state of one's body. As Tye has argued, our moods are representations of physical changes to our "bodily landscapes":

For each of us, there is at any given time a range of physical states constituting functional equilibrium. Which states these are might vary from time to time. But when functional equilibrium is present, we operate in a balanced, normal way without feeling any particular mood. When moods descend on us, we are responding in a sensory way to a departure from the pertinent range of physical states. (Tye 1995, p. 129)

Certainly more would need to be said to make this analysis a plausible one. But if it could be developed, $\mathrm{NIM}$ - the claims that moods are typically non-intentional - would be falsified. Even if moods can fail to be directed outward to the world or to objects or properties within it, they would nonetheless have a sort of inward directedness by representing something about our physiology.

Interestingly, this kind of inward directedness is best described as generalized in a way reminiscent of the previous subsection. In contrast to emotions, which are inwardly directed at particular bodily changes and are thus specific sensory representations, moods are inwardly directed more generally at the body overall and are thus generalized sensory representations. This parallels the difference between moods and emotions with respect to outward directedness. Whatever intentional content moods may have, whether it be inward or outward, it seems to be of a more diffuse or generalized nature than the intentional content of emotions.

\footnotetext{
${ }^{23}$ See, e.g., Tye 1995, pp. 111-116; Crane 1998.

${ }^{24}$ Moreover, the representationalist aims to identify the phenomenal character of emotion with this representational content. See, e.g., Tye 1995.
} 


\subsection{Hybrid Theories}

Of course, the two accounts just considered - moods as generalized representations of the world and moods as (generalized) representations of the body - are not mutually exclusive. In discussing the intentionality of moods, several philosophers have recently offered what we might call hybrid views - views that see the intentionality of moods as consisting in both outward and inward directedness. One particularly well-developed hybrid theory has been offered by Peter Goldie, who claims that mood experiences involve two kinds of feelings, what he calls bodily feelings and feelings toward. ${ }^{25}$ For Goldie, both of these are intentional. A bodily feeling is intentional in being inwardly directed toward one's body and the changes that it is undergoing. A feeling toward, in contrast, is outwardly directed - it is an "unreflective emotional engagement with the world beyond the body." (Goldie 2002, p. 241) ${ }^{26}$

What then, are we to make of NIM, the claim that moods are typically non-intentional? The discussion throughout this section makes this claim look increasingly implausible. Despite the truth of UM, that is, despite the fact that moods are typically not directed at anything in particular, it seems implausible that they are typically non-intentional. NIM should thus be rejected.

While the truth of NIM would have made our case against representationalism an easy one, it's important to note that the falsity of NIM does not settle the issue in favor of the representationalist picture. There remain several argumentative strategies available to the anti-representationalist.

First, even if moods are typically intentional, there could still be isolated cases where they are non-intentional. Consider a weaker version of NIM, the Weak Non-Intentionality of Moods:

(WNIM) Moods are sometimes non-intentional.

WNIM would still be enough to falsify the representationalist treatment of moods (and thus unrestricted representationalism more generally). To develop our anti-representationalist case, then, we might explore whether some instances of moods, be they cases of generalized depression or free-floating anxiety or something else altogether, are best understood as being about nothing at all (as opposed to just nothing in particular).

Though I think this strategy has considerable potential, I will leave this fight for another day. In what follows I want to pursue a different line of attack against representationalism. Going forward, I'll simply grant the representationalist that moods have - not just typically, but always - the kind of generalized intentionality (either outward, inward, or both) detailed above. But just as we might agree

\footnotetext{
${ }^{25}$ Although Goldie is concerned primarily with the intentionality of emotions, recall that for him the difference between emotion and mood is simply one of degree.

${ }^{26}$ Tye also offers a hybrid account (Tye 2008).
} 
that perceptual experiences are always intentional while rejecting representationalism about perception, so too we can agree that moods are always intentional while rejecting representationalism about moods. For representationalism to be true of moods, it must be the case not only that moods have intentional content, but also that their phenomenal content reduces to this intentional content. It is this latter claim that I will explore - and dispute - in what follows.

\section{Against Reductive Representationalism}

For the representationalist, a state's phenomenal character is nothing over and above its intentional content; what it is like to be in a certain state is just a matter of what the state represents. So consider what this representationalist picture means for moods. Above we saw three different ways to understand the intentional content of such a state - as outwardly directed, inwardly directed, or a hybrid of the two. Broadly speaking, then the representationalist has the following three options:

Outward Directedness: What it is like to be in mood $\mathrm{M}$ is to have a certain kind of outwardly focused representational content.

Inward Directedness: What it is like to be in mood $\mathrm{M}$ is to have a certain kind of inwardly focused representational content.

Hybrid Directedness: What it is like to be in mood $\mathrm{M}$ is to have both a certain kind of outwardly focused representational content and a certain kind of inwardly focused representational content.

In Section 2.1, we distinguished three different ways that moods might be outwardly directed: as directed at a changing series of objects, as directed at the world as a whole, or as directed at unbound properties. Thus, there are three different ways of pursuing the first option and correspondingly three different ways of pursuing the third hybrid option. To my mind, however, all of these options fail. Even on the assumption that moods have intentional content, this content does not seem able to account for the phenomenology. As William Lycan has put the point, when it comes to mental states like moods, the intentional content "does not loom very large in the overall phenomenal character of the mental state in question." (Lycan 2006)

This strikes me as especially clear with respect to Inward Directedness. Granted, if one has adopted a theory that sees moods on a continuum with emotions, the fact that the phenomenology of emotions might plausibly be (at least partly) explained in terms of inward intentional content makes it tempting to suppose that the phenomenology of moods should also be explainable (at least partly) in terms of inward intentional content. But this temptation must be avoided. When I am briefly overcome with anger after a driver cuts me off on the freeway, I am often vividly aware of the changes my body undergoes - I feel my face getting flushed, and my heart beating faster, and the trembling in my hands. Things seem quite different when, over the course of several hours, or several days, I am in an irritable mood. I feel on edge, prone to snap, and not quite myself. But this phenomenology does not seem 
rooted in the state of my body, even in some generalized way. Though my body may indeed be in a different physiological condition from its baseline, this physiological fact is not something of which I am aware, let alone vividly so. In short, even if my physiological condition is represented by my mood, this intentional content is far too minimal to capture the rich phenomenological aspects of what it's like to be in irritable mood. The point seems to apply just as strongly - or perhaps even more so - when we reflect on other moods, like states of free-floating anxiety or generalized elation. In contrast to the inward intentional content of emotions, the inward intentional content of moods is too impoverished to do the work that it is being assigned. ${ }^{27}$

The situation initially looks better for the representationalist with respect to Outward Directedness, since here the intentional content is somewhat more robust. Even here, however, the intentional content is insufficient to capture the phenomenology. For the representationalist, the phenomenal character of moods reduces to the intentional content - that's simply what the phenomenal character is. Importantly, this means that there can be no change in the intentional content of a mood without a corresponding change in the phenomenal character, and likewise, that there can be no change in the phenomenal character of a mood without a corresponding change in the intentional content. As I will suggest, neither of these claims is plausible.

Let's start with the suggestion that moods are intentionally directed at a changing series of objects in the world. As noted above, when someone is depressed, everything to which she turns seems awful and black; when she's elated, everything to which she turns seems wonderfully rosy. So now consider a few moments in the life of an elated person. As she walks along outside, she encounters an ever-changing landscape of sights, sounds, and smells. Today, given her mood, the storefront across the way doesn't seem nearly as shabby as it usually does; the face of her taciturn neighbor doesn't strike her as quite as menacing; the car horns fail to disturb her and likewise for the odors emanating from the overflowing dumpster at the curb. Today, everything she passes seems wonderful and new. Insofar as her mood is directed at a changing series of things in the world, the intentional content of her mood is constantly changing. But what of the phenomenological character of her mood? Is there any reason to suppose that this must be changing as well? Granted, as she walks along, there will be changes to her visual phenomenology, and likewise to her auditory and olfactory phenomenology. But these sorts of changes are distinct from the phenomenology of the mood itself, which need not vary as she makes her way out in the world. ${ }^{28}$

In saying this, I do not mean to suggest that the phenomenology of moods always remains completely static. We often refer to moods as waxing and waning, and I take these to be

\footnotetext{
${ }^{27}$ Here also it's worth briefly noting that one woman's modus ponens is another's modus tollens. Given the phenomenological similarity between emotions and moods, representationalists are inclined to think that the inwardly directed account that they've offered for emotions can be applied, mutatis mutandi, to moods. In my view, however, the discovery that this account cannot be easily applied to moods gives us reason to call into question this treatment of emotions as well. But I do not have the space here to pursue this point.

${ }^{28}$ Perhaps there might be some component of the intentional content that remains unchanged as her mood is directed at a changing series of objects of the world. My suspicion is that this thought is best worked out in connection with Mendelovici's view of moods as representing unbound emotion properties (see below).
} 
phenomenological descriptors. Over the course of a day in which one feels elated, the elation might be felt more deeply, more intensely, at one moment than at another. But what's important is that these changes do not seem at all tied to the changing series of worldly objects at which one's mood is directed. Thus, not only do we have changes in the intentional content of the mood that are not reflected in corresponding changes in the phenomenal character of the mood, but we also have changes in the phenomenal character of the mood that are not reflected in corresponding changes in the intentional content.

Faced with this latter point, I envision the representationalist responding along the following lines: "An elated mood represents worldly objects as being rosy and wonderful. When my mood waxes, I'm representing the relevant worldly object as being rosier and more wonderful; when my mood wanes, I'm representing it as being less rosy and wonderful." This suggestion, however, does not seem faithful to our experience of moods. Consider a new father who has been in an elated mood for hours, ever since his child was born. As he rocks his daughter to sleep in his arms, his elation deepens. Must we suppose that as this happens, his daughter starts to seem rosier and more wonderful to him? If his elation lessens, must we suppose that she starts to seem less rosy and wonderful to him? The point here is not one about concepts. Even if we suppose, along with many representationalists, that the representational content of experience is nonconceptual content, my claim still holds: A person's mood can change phenomenally even when there is no change to the way the object of the mood seems to that person.

The fact that the phenomenology can change without any corresponding changes to the intentional content shows why the representationalist is no better off supposing that the mood is directed at the world as a whole, rather than at a changing series of objects in the world. Insofar as the phenomenology of a mood can change without the world seeming different, the representationalist's reduction will be no more successful here than on the previous way of spelling out Outward Directedness.

Granted, since on this second view the mood is continually directed at the same object, the world, it does seem better able than the previous view to explain situations in which a mood's phenomenology remains constant. But I think even here there are problems for the view. After all, the following claims seem perfectly coherent, and (unless we're in the grips of a theory) I don't see why we shouldn't take them at face value:

My depression hasn't worsened since yesterday, but today everything seem blacker.

My fearfulness hasn't lessened any, but the world seems less scary today.

Compare also claims like the following, which likewise seem perfectly coherent:

The world doesn't seem any more worrying today, yet somehow my anxiety has intensified.

The world doesn't seem any blacker today, yet I find myself sinking deeper into depression. 
All of these claims serve to falsify the suggestion that the phenomenal character of a mood reduces to the mood's representing the world in a certain way.

That brings us to the third way of spelling out Outward Directedness, namely, Mendelovici's suggestion that a mood's intentional content be explained in terms of sui generis unbound emotionproperties. Emotion experiences are hypothesized to represent these properties as bound to objects so, for example, when I am scared of a snake, my experience of fear represents the snake as scary*. In contrast, when I am in a fearful mood, my mood represents scariness* as unbound.

One clear advantage of Mendelovici's view is its ability to account for the fact that moods often present themselves phenomenally as free-floating in nature. But while it gets right the fact that fearful moods, for example, don't seem to represent anything in particular as scary*, it's not clear that this means that they represent unbound scariness* instead. In large part, this is because it's not entirely clear what it is to represent unbound scariness*. Perhaps it might it be something like the representation: There's scariness* about. But this seems less a case where scariness* is unbound than a case in which we're representing scariness* as bound to something unidentified or unidentifiable, a situation more like a representation of scariness*-bound-to-we-know-not-what. Thus, the plausibility of this view rests in part on whether we can be given an adequate explanation of the suggestion that properties can be represented unbound.

Even given such an explanation, however, some of the same problems we raised above for the other versions of Outward Directedness arise again here. To account for the fact that moods vary in their phenomenology over time, Mendelovici will have to identify appropriate changes in the intentional content. There are not many options here. Since the emotion-properties are hypothesized to occur unbound, there is no intentional object to change. Presumably, then, there will have to be different emotion-properties represented at different times - mild scariness*, moderate scariness*, and so on. Perhaps the proliferation of properties is not itself something to worry about. But what is worrying is the fact that it seems we can experience phenomenal changes to our mood without corresponding intentional changes of this sort.

Consider again the father rocking his newborn to sleep in his arms. Above, in arguing against a different version of Outward Directedness, I suggested that it was implausible to suppose that his daughter must seem different to him - slightly more wonderfully rosy - as his elation deepens. Since on Mendelovici's view, his generalized feeling of elation does not represent his daughter, she can avoid this implausible supposition. But the victory is short-lived. Her view commits her to something equally implausible, since one's deepening elation doesn't seem to need to correspond to a change from rosiness* to deeper-rosiness* - that is, from unbound-rosiness*-seeming to unbound-deeperrosiness*-seeming. The point seems to apply to other moods as well. Must the degree of my fearful mood correspond to the degree of unbound-scariness*-seeming? Must the degree of my depression correspond to the degree of unbound-blackness*-seeming? In my view, the answer to both these questions is clearly "no." In short, the switch to unbound properties does not seem to improve the 
representationalist's chances for a successful reduction of phenomenological character to intentional content. $^{29}$

What then of hybrid theories? Although Inward Directedness and Outward Directedness are individually problematic, one might naturally think that the representationalist could solve the problems mentioned above by synthesizing the two in some way. In particular, one might think the inward and outward intentional content of a mood might be jointly sufficient to capture its phenomenal character even if neither such content is individually so.

In evaluating this suggestion, it's first important to note the unified nature of the phenomenal character of moods. Unless the inward and outward content can be integrated in some way, a hybrid view will not get off the ground. ${ }^{30}$ But even if some sort of unification can be achieved, other problems remain. For example, the addition of inward intentional content to outward intentional content will be of no help to the representationalist if the phenomenal character of a mood can stay the same even while the outward intentional content changes. Thus, the hybrid view looks to have no more promise than the other views we have here considered.

\section{The Failure of Transparency}

The discussion of the previous section suggests that the representationalist reduction fails with respect to moods. Even if we concede that NIM in false - that is, even if moods are typically intentional - the representationalist needs to do more than simply identify some intentional content associated with moods. The intentional content that she finds must be such that the phenomenal character of moods could plausibly be said to reduce to it. And this she has not done.

My discussion thus far has not ruled out that the representationalist might light upon some source of intentional content not yet discussed that would account for the phenomenal character of moods. In this concluding section, however, I would like to offer at least one compelling reason to think that this won't happen. We noted at the start of the paper that the driving motivation for representationalism has been its promise to solve the hard problem of consciousness. This motivation, however, is loaded. It does not help to show that the theory might be true; after all, the hard problem might simply be unsolvable. In arguing for their theory, representationalists thus tend to rely upon a second, less loaded motivation: the so-called transparency of experience.

Experience is said to be transparent in the sense that we 'see' right through it to the object of that experience, analogously to the way we see through a pane of glass to whatever is on the other side

\footnotetext{
${ }^{29}$ Another way to put these points is to return to Mendelovici's highlighter analogy, discussed above. As our mood waxes and wanes, it does not seem that there need to be corresponding changes to the shade of the highlighter ink. Likewise, as the shade of the highlighter ink changes, it does not seem that there need to be corresponding changes to the felt intensity of the mood.

${ }^{30}$ Mendelovici (this volume) pushes this point against hybrid views.
} 
of it. Considerations of this sort were introduced into the contemporary debate about by Gilbert Harman. In a now famous passage, Harman claimed:

When Eloise sees a tree before her, the colors she experiences are all experienced as features of the tree and its surroundings. None of them are experienced as intrinsic features of her experience. Nor does she experience any features of anything as intrinsic features of her experiences. And that is true of you too. There is nothing special about Eloise's visual experience. When you see a tree, you do not experience any features as intrinsic features of your experience. Look at a tree and try to turn your attention to intrinsic features of your visual experience. I predict you will find that the only features there to turn your attention to will be features of the presented tree... (Harman 1990, p. 667) ${ }^{31}$

If representationalism were true, then we would have a clear explanation of transparency: The reason that we cannot attend to intrinsic features of our experience is that there are none; rather, there are only representational features. ${ }^{32}$ In this way, intuitions about transparency play a key role in building a case for the representationalist view.

What exactly it means to say that experience is transparent, and whether the way in which it is transparent really does support representationalism, has recently been the subject of much debate. ${ }^{33}$ Importantly, however, there is a wide consensus that some version of the transparency thesis seems plausible with respect to ordinary visual experiences. Things are quite different when it comes to moods. Defenders of transparency about visual experiences have rarely attempted to extend the transparency thesis to mood experiences, presumably because in this domain the thesis has no purchase. $^{34}$ Many would go further and claim that it has no purchase even for emotions. As Ronald De Sousa has noted, in comparison with perceptual experience, emotions are relatively opaque: When someone tries to focus her attention on her jealousy or anger or joyfulness, her attention doesn't go out into the world; in contrast, when she tries to focus her attention on the world, she often ends up focusing only on her own state of mind. (De Sousa 2004, p. 64) ) $^{35}$

For transparency to be true of moods, it would have to be the case that whenever one tried to focus one's attention on a mood itself, one's attention would slip right through the experience to something else - perhaps worldly objects, or perhaps the state of one's body. ${ }^{36}$ But this isn't at all what happens. It might be that in attending to my experience of blueishness, I don't (or even can't) attend directly to the blueishness of my experience itself. But in attending to my experience of elation, it seems most natural to describe what I'm attending to as the elation itself. I'm not simply attending to some feature of the world, or to a feature of a changing series of things, or even to some unbound feature. Rather, I focus directly on what it feels like to be elated.

\footnotetext{
${ }^{31}$ See also Tye 1995, p. 30.

${ }^{32}$ It is generally assumed in this discussion that representational features are non-intrinsic.

${ }^{33}$ See, e.g., Kind 2003.

${ }^{34}$ Here Michael Tye is a striking exception, e.g., Tye 1995.

${ }^{35}$ See also Deonna and Teroni 2012, pp. 68-9.

${ }^{36}$ Transparency seems especially hard to make out on a view like Mendelovici's. Given her analysis of the intentional content of moods, it looks like she would have to claim that whenever one attends to one's mood one's attention slips through and one ends up attending to unbound properties instead. But what could it mean to attend to an unbound property?
} 
If this is right, if I can focus directly on what it feels like to be elated - on the felt quality of the mood, an intrinsic feature of it - then representationalism about moods faces a serious threat. On a representationalist view, there are no such intrinsic features. Thus, the problem for the representationalist is not a matter of fine-tuning their specification of the intentional content of moods. No matter how the intentional content is specified, the failure of transparency suggests that there is more to the phenomenology than can be captured by that content.

Undoubtedly the representationalist will have something to say in response to the above line of argument. But even if I have not yet shown that transparency is false with respect to moods, the reflections of this concluding section make clear that transparency is by no means obviously true with respect to moods. And even this much weaker conclusion plays an important role in the case against representationalism. In the perceptual sphere, transparency is taken to be an obvious phenomenological fact in need of explanation and thus is invoked to show not just that representationalism is a viable option but that it must be true. With respect to moods, in contrast, transparency is not an obvious phenomenological fact. We thus have no special reason to think that representationalism about moods has any promise.

In short, even if the representationalist were able to explain away the seeming failure of transparency with respect to moods, the key motivation for her theory would have been undermined. This result, combined with the reflections in the previous section suggesting the failure of existing representationalist theories, provides compelling reason to think that the representationalist reduction of moods cannot be achieved.

\section{Bibliography}

Antony, Louise. 1997. "What it's like to smell a gardenia." The Times Literary Supplement 4897 (February 7).

Baier, Annette. 1990. "What Emotions are About." Philosophical Perspectives 4: 1-29.

Block, Ned. 1996. "Mental Paint and Mental Latex." In Enrique Villaneuva, ed., Philosophical Issues 7, Perception,19-49. Atascadero, Calif.: Ridgeview.

Byrne, Alex. 2001. "Intentionalism Defended." Philosophical Review 110: 199-240.

Chalmers, David. 2004. "The Representational Character of Experience." In Brian Leiter, ed., The Future for Philosophy. Oxford: Oxford University Press.

Chalmers, David. 1995. "The Puzzle of Conscious Experience." Scientific American.

Crane, Tim. 1998. "Intentionality as the mark of the mental." In Contemporary Issues in the Philosophy of Mind, ed. Anthony O’Hear, pp. 136-157. Cambridge: Cambridge University Press.

Delancey, Craig. 2006. “Basic Moods.” Philosophical Psychology 19: 527-538. 
Deonna, Julien A. and Fabrice Teroni. 2012. The Emotions: A Philosophical Introduction. New York: Routledge.

Richard Davidson and Paul Ekman. 1994. "Afterword: How Are Emotions Distinguished From Moods, Temperament, and Other Related Affective Constraints?" In Paul Ekman and Richard Davidson, eds., The Nature of Emotion. Oxford: Oxford University Press, pp. 94-96.

De Sousa, Ronald. 2010. "Emotion." Stanford Encyclopedia of Philosophy.

Dretske, Fred. 1995. Naturalizing the Mind. Cambridge, Mass.: The MIT Press.

Fish, William. 2005. "Emotions, Moods, and Intentionality." In Intentionality Past and Future, ed. G. Forrai and G. Kampis. Rodopi Press, pp. 25-35.

Frijda, Nico. 10993. "Moods, Emotion Episodes, and Emotions." In J. Haviland and M. Lewis, eds., Handbook of Emotions. New York: Guilford, pp. 381-403.

Goldie, Peter. 2002. "Emotions, feelings, and intentionality." Phenomenology and the Cognitive Sciences 1: 235-254.

Goldie, Peter. 2000. The Emotions. Oxford: Oxford University Press.

Graham, George. 1990. "Melancholic Epistemology." Synthese 82: 399-422.

Griffiths, Paul E. 1997. What Emotions Really Are: The Problem of Psychological Categories. Chicago: The University of Chicago Press.

Harman, Gilbert. 1990. "The Intrinsic Quality of Experience." In The Nature of Consciousness, Ned Block et al, eds. Cambridge, Mass.: The MIT Press (1997), 663-75.

James, William. 1884. "What is an Emotion?" Mind 9: 188-205.

Johnson, Gregory. 2009. "Emotion." Internet Encyclopedia of Philosophy.

http://www.iep.utm.edu/emotion/

Kenny, Anthony. 1963. Action, Emotion and Will. London: Routledge \& Kegan Paul.

Kind, Amy. 2008. "How to Believe in Qualia." In E.O. Wright, ed., The Case for Qualia, pp. 285-298.

Cambridge, Mass.: MIT Press.

Kind, Amy. 2007. "Restrictions on Representationalism." Philosophical Studies 134: 405-427.

Kind, Amy. 2003. "What's So Transparent About Transparency?," Philosophical Studies 115: 225-244.

Kupperman, Joel. 1995. "An Anti-essentialist View of the Emotions." Philosophical Psychology 8: 341351. 
Lazarus, Richard. 1994. "Appraisal: The Minimal Cognitive Prerequisites of Emoion." In P. Eckman and R.J. Davidson (eds.), The Nature of Emotions. Oxford: Oxford University Press.

Lormand, Eric. 1985. "Towards a Theory of Moods." Philosophical Studies 47: 385-407.

Lyons, William. 1980. Emotion. Cambridge: Cambridge University Press.

McGinn, Colin. 1991. "Consciousness and Content." In The Nature of Consciousness, Ned Block et al, eds. Cambridge, Mass.: MIT Press (1997), 295-307.

Mendelovici, Angela. This volume. "Pure Intentionalism about Moods and Emotions."

Montague, Michelle. 2009. "The Logic, Intentionality, and Phenomenology of Emotion." Philosophical Studies 145: 171-192.

Price, Carolyn. 2006. "Affect Without Object: Moods and Objectless Emotions." European Journal of Analytic Philosophy 2: 49-68.

Prinz, Jesse. 2004. Gut Reactions: A Perceptual Theory of Emotion. Oxford: Oxford University Press.

Searle, John R. 1983. Intentionality. Cambridge: Cambridge University Press.

Sizer, Laura. 2000. "Towards a Computational Theory of Mood." British Journal for the Philosophy of Science 51: 743-769.

Solomon, Robert. 1976. The Passions. New York: Anchor Press/Doubleday.

Solomon, Robert. 1993. The Passions: Emotions and the Meaning of Life. Indianapolis: Hackett.

Thalberg, Irving. 1964. "Emotion and Thought." American Philosophical Quarterly 1: 45-55.

Tye, Michael. 1995. Ten Problems of Consciousness. Cambridge, Mass.: MIT Press.

Tye, Michael. 2008. "The Experience of Emotions: An Intentionalist Theory." Revue Internationale de Philosophie 62: 25-50. 